\title{
José María Arguedas
}

"Me retiro ahora porque siento, he comprobado que ya no tengo energía e iluminación para seguir trabajando, es decir para justificar la vida", escribió José María Arguedas en una carta dirigida al rector y los estudiantes de la Universidad Agraria de Lima el 27 de no. viembre último; en uno de los salones de esa Universidad se disparó, el 28, un tiro en la sien; murió el 2 de diciembre, casi cuatro días después. Ya en abril de 1966 Arguedas había intentado matarse con una sobredosis de barbitúricos.

"Y ahora estoy otra vez a las puertas del suicidio. Porque, nuevamente, me siento incapaz de luchar bien, de trabajar bien. $\mathrm{Y}$ no deseo, como en abril del 66, convertirme en un enfermo inepto, en un testigo lamentable de los acontecimientos", escribió en el capítulo inicial de su novela El zorro de arriba v el zorro de abajo, que publicó la revista Amaru (Lima, núm. 6, abril-junio 1968).

Seis meses antes de matarse, en su respuesta a Julio Cortázar ("Inevitable comentario a unas ideas de Julio Cortázar", en Arbol de letras, Santiago de Chile, julio, 1969), Arguedas había escrito: "Yo soy un hombre feliz y continuaré siéndolo mientras pueda seguir trahajando, aquí o allá. Esa respuesta asumía una falsa polémica: la buena o la mala conciencia de escribir en América Latina o en el exilio, deducida por Cortázar en su reportaje de Life (7 de abril, 1969) a partir del texto de Arguedas publicado por Amaru. No es del caso insistir en ese malentendido: Arguedas en su respuesta demuestra hasta la obviedad que de eso se trata. Pero tal vez no sea casual que el escritor peruano y el escritor argentino se hayan enfrentado: posiblemente ellos suponen dos legítimas opciones del arte y la cultura latinoamericanos. $O$ más bien una misma posibilidad en dos lenguajes: para Cortázar, como para Arguedas, la literatura es la búsqueda de un destino individual dentro de un destino común.

Arguedas podía considerarse un hombre feliz asumiendo su destino 
de escritor en el formidable trabajo de su obra. Más admirable todavía porque ese trabajo estaba amenazado permanentemente por un profundo malestar personal, que se remonta a 1944, según ha contado, y más atrás aún: a la infancia. Las sobrecogedoras primeras páginas de su última novela fueron escritas por prescripción médica, en Santiago de Chile, como casi toda su obra última, escrita en un agudo exorcismo. Su última novela asume decididamente el punto de vista de su muerte irrevocable: el suicidio, que aparece en sus distintos libros, se convierte en el tema central, "el único cuya esencia vivo y siento", en la perspectiva del recuento final. Las páginas primeras de esa novela son por eso un diario abierto, sin plan ni orden previo; en su carta última Arguedas dice que esa novela queda "casi inconclusa" y que incluye un "Ultimo diario"; se sabe también que el plano de ficción acontece en Chimbote, un puerto de pescadores transformado por la explosión industrial.

Ignoro si alguien pueda explicar la complejidad del malestar de Arguedas sin simplificar su extraordinaria agonía. Sólo sé que en su obra esa agonía aparece como una insoluble escisión: el drama intimo de la ambigüedad entre su raigambre indígena y su desajuste dentro de la cultura moderna. En uno de sus cuentos más intensos, "El forastero" (1964), Arguedas es el hablante lacerado por la soledad más absoluta; su emblema es el cóndor, el pájaro de las punas heladas del Perú. Ya desde sus primeros textos (Agua, 1935) el hablante autobiográfico - un niño acosado por la injusticia y la rebeldía - muestra la ambigüedad mestiza como su signo y destino: su identidad profunda con el mundo indigena, del que lo separa otro destino, ligado a la conciencia y la crítica. Ese mundo complejo era un debate poético: un exorcismo hecho de pavor y piedad. Al cesar la fuerza de esa liberación agónica se comprende que Arguedas decidiese morir; en sus libros la recurrente proximidad de la muerte extremó la intensidad de los hechos, de la escritura fervorosa y asombrada.

La ambigüedad esencial del mestizo -escindido entre su raíz indígena y su profundo exilio- aparece como uno de los debates más intimos de la narrativa de Arguedas. Es el debate de la magia y la crítica, de la piedad y la rebeldía. La soledad es la consecuencia de ese proceso. Pero también el sueño de un destino común.

Por eso en su novela más importante, Todas las sangres (1964), Arguedas busca hacer estallar la pasividad de la raíz indígena: mostrando la depredación social de un medio tradicional en proceso de cambio, nos presenta al indígena ingresando al destino social -que la 
múltiple dependencia del Perú le niega- con una fuerza intacta y magnífica. Esa explotación poética no es un rezago romántico ni una posición anacrónicamente indigenista. Es preciso considerar que Arguedas supone otra dimensión del indigenismo; en realidad, el término resulta insuficiente: Arguedas continúa un diálogo cultural que posiblemente habia iniciado en el Perú el Inca Garcilaso, que había prolongado Vallejo. La respuesta de Arguedas es latinoamericana: tal vez una de las últimas respuestas de un posible destino latinoamericano a las invasiones depredantes de la dependencia y la despersonalización que supone el mundo moderno. No es casual, por ello mismo, que en esa novela el marco crítico esté propuesto por la situación del subdesarrollo peruano: es dentro de las miserias de la dependencia - las sucesivas dependencias de las clases sociales, de los poderes económicos y políticos, del país todo al imperialismo- donde el deseo liberador de la poesía encuentra la vida intacta - intacta aun en su marginación y humillación- del mundo indígena como final y expectante posibilidad de la justicia. Así, la crítica se convierte en el deseo; la conciencia, en el sueño de otra realidad; la literatura en la búsqueda poética de un destino común.

La obra de Arguedas es una antropología profunda que se resuelve en poesía. Nos muestra los conflictos sociales de un país en proceso de cambio, pero su sueño mayor es la personalización, la construcción de una entidad humana que a partir de sus propios valores obtenga su historia. Pero nada en esta obra es programático: al contratio, el debate cultural que ella muestra es una aventura que desafía el racionalismo simple, que se abre como ampliación poética de lo real. Cortázar ha escrito que la gran literatura de algún modo implica el sueño paradisíaco. $Y$, en efecto, nuestras mejores novelas suponen un paraíso perdido que refracta los hechos humanos: Pedro Páramo, Rayuela, Paradiso, Cien años de soledad, de distinta manera nos hablan de esa pérdida o esa persecusión. Pero también, al mismo nivel, en otros textos la poesía se convierte en la añoranza de la utopía. Ya no la utopía de una América pródiga. Más bien, la desgarrada utopía de una América Latina con historia. También ese vacío de la Historia supone una exploración poética, un deseo agónico. Esa agonía recorre la obra lde Arguedas: un destino común, para él, es un largo y apasionado debate, hecho entre la desesperación y la rebeldía, entre la magia y la añoranza. Lo que hace único a Arguedas es el hecho de que su exploración reconoce la inminencia de la muerte, sombra del deseo: por eso Arguedas es un escritor trágico. Como Vallejo. 
La suerte de la utopia contemporánea es haberse convertido en tragedia: no es más un idealismo coherente, una alegoría perfecta que acusa a la realidad perfectible. En la formidable añoranza del Inca Garcilaso el mundo incaico es suficiente; y su destino es el privilegio de la poesía: él es el intérprete porque es el mestizo y posee una lengua (cf. Alberto Escobar: Patio de Lelras, Lima, 1965). En nuestro tiempo la utopía es más bien un sueño que en lo imposible se amplía, en el deseo de la Historia que nos personifica. España, aparta de mí este cáliz construye con la palabra poética esa utopía cuya plenitud asume la muerte como identidad esencial del yo y el tú en el nosotros sublevado. Todas las sangres construye con la palabra critica otra utopía cuyo apocalipsis social supone el encuentro de una vida que contradice la sumisión de la dependencia, y esta operación crítica es el sueño totalizador de la poesía como destino común, como posible historia.

Arguedas habia tratado de ponernos en contacto con una tradición relegada: la vida y la poesía de los pueblos indígenas del Perú. En su magnífico relato "La agonía de Rasu-Niti" esa tradición aparece en su dimensión mágica y en su tragedia también: un viejo bailarín danza su última danza y mira su vida y su muerte, su tránsito y su perpetuidad en el rito que lo devuelve a la tierra, a una vida impersonal y unánime. Ese relato, y también la dimensión mítica que subyace en su obra, muestran en Arguedas la presencia viva de aquella tradición indígena, que la poesía nos devuelve. No en vano Arguedas trabajó desde una perspectiva poética para conectar el mundo quechua y el idioma español: moduló una lengua personalísima, que traduce la complejidad anímica y los ritmos orales de una tradición hablada. Un diálogo que no es sólo animista, encantatorio del medio, sino que sobre todo es una reconstrucción del hombre en el mundo, su posibilidad de morada y su recomposición mágica, pero también su crítica y su ampliación. Su fe en el mundo indígena peruano es también su agonía: Arguedas advertía como pocos la situación de increíble injusticia y depredación en que se debate ese mundo, y su obra expone esa situación mejor que ninguna otra; pocas veces la literatura ha descubierto formas tan pavorosas de injusticia y sufrimiento. Pero a diferencia de las literaturas simplemente testimoniales o retóricamente de denuncia, la de Arguedas muestra la injusticia en el contexto complejo de las dependencias sociales y raciales, y también la suntuosidad casi increíble de las relaciones humanas en ese contexto, que adquieren forma y relevancia en el lenguaje. 
Admiraba las conquistas del mundo moderno (cándidamente cantó cn quechua el poder del jet) pero creía que el Perú y América Latina poseían la capacidad de una respuesta original; su obra, precisamente, es cl sueño de esa posibilidad. Había sido uno de los primeros etnólogos que hablaron del impresionante mito del Inkarrí. Según este mito (contemporáneo entre los indios peruanos) el hombre blanco dio muerte al dios indígena Inkarrí, y enterró su cabeza en el Cuzco; pero dentro ie la tierra el dios está vivo: su cuerpo crece otra vez y un día se habrán completado sus brazos y sus piernas; se pondrá entonces de pie y nuevamente la justicia volverá a la tierra. La justicia en esta tierra: un pueblo cuyo futuro ha sido brutalmente negado, sueña en este mito su redención.

Llenar un destino vaciado, acceder a la historia: en la última década esa ambición de la poesía profunda señaló a buena parte de la literatura latinoamericana; en el Perú, un sueño semejante tiene en Arguedas su desgarrado ejemplo. A través de la pura añoranza, de la libre imaginación, aquella ambición central - el sueño de otra vida, de otro tiempo, la reconciliación de la inocencia- ha creado en América Latina una literatura abierta, ligada por la crítica y la poesía. El revés de ese sueño no es menos real: la obra de Arguedas acaso finalmente nos dice que aquella ambición es un sueño trágico.

En uno de sus primeros textos (prólogo a Canto kecbwa, 1938) José María Arguedas escribió: "Yo puedo probar lo contrario", al negar la suposición de que los indios del Perú conforman "una raza sin porvenir". Su vida, y su muerte también - una misma y única prueba-, son el trágico sueño de una raza que es un lenguaje, y también un destino común.

\section{ADDENDA I: NOTICIA BIO-BIBLIOGRÁFICA}

José María Arguedas nació en Andahuaylas, un pueblo de la sierra sur del Perú, en 1911. Su padre era un abogado viajero y él se crió entre los indios, en la comunidad de San Juan de Lucanas, y en la hacienda Viseca; así su lengua materna vino a ser el quechua y sólo adolescente aprendió el español. "A los doce años de edad me sacaron de. la quebrada (Viseca). Mi padre me llevó a recorrer otros pueblos. Un año en Abancay, otro en Pampas, otro en Chalhuanca, en Cangallo, en Ayacucho, en Huaytará, en Yauyos, en Andahuaylas... Pero un año llegué a los valles del Apurímac. Allí tenía haciendas un pariente lejano 
de mi padre. Eran cuatro haciendas grandes, de cañaverales. El dueño me mandó a una de ellas, para no verme a su lado. El vivía en la hacienda Karkeki. Este viejo "tenía 400 indios" en sus tierras. Esa indiada no tenía pueblo, no tenía casa, ni un pedacito de tierra: todo era del viejo... Esa indiada no sabía cantar... "¿Por qué será, que no cantan?"', decía yo. Y tenía pena. Algunas noches los visitaba y junto a ellos cantaba los waynos de Ayacucho, de Abancay, de Coracora. Pero casi no oían. "Bonito, niñucha!" - decían... Una noche el viejo había oído tocar una quena, en el caserío de Karkeki y fue al rancherío, ocultándose; llegó hasta la puerta del cuarto donde tocaban la quena, y entró a la casa diciendo: "IIndios, a esta hora se reza!" Pidió la flauta y la pisoteó en el suelo". (Prólogo, Canto kechwa). Arguedas hizo sus primeros estudios en San Juan de Lucanas, Puquio y Abancay; sus estudios de secundaria en Ica, Huancayo y Lima. En 1931 ingresó a la Universidad Nacional Mayor de San Marcos. Fue empleado auxiliar en la Administración de Correos entre 1932 y 1937. Entre ese año y el 38 estuvo preso por haber participado en una protesta universitaria contra el fascismo; sus experiencias en la cárcel constituirían más tarde su novela $E l$ sexto, nombre éste de un presidio peruano. Emilio Adolfo Westphalen y Manuel Moreno Jimeno también estuvieron en prisión, en 1937, por firmar un memotial de adhesión a la lucha de la República española; era dictador entonces Oscar R. Benavides, un militar que negó la visa de ingreso a los escritores republicanos. En 1939 se casó con Celia Bustamante y ese mismo año fue a Sicuani (Cuzco) como profesor del Colegio Nacional de Sicuani, y permaneció allí hasta 1941. Trabajó luego en la Sección de Folklore y Artes Populares del Ministerio de Educación Pública (1942-1956) y en el Museo de la Cultura Peruana (19561963). Había vivido en España un año preparando su tesis doctoral (1963), que apareció en 1968 (Las comunidades de España y del Perú); califica al libro de "una buena crónica; tiene algo de novela y está salpicado de cierto matiz académico, perdonable y hasta amenamente pedantesco y temeroso a la vez". Fue Director de la Casa de Cultura del Perú (1963-1964) y Director del Museo de la República (1964). Ha sido profesor en San Marcos, la Universidad Nacional de Educación y la Agraria, donde dirigía el Departamento de Etnología. En abril de 1966 intentó matarse. En 1967 se casó con Sibila Arredondo. Fue a La Habana en 1968, y vivió alternativamente en Lima, en Chimbote, en Santiago de Chile; preparaba ya el desenlace, buscaba no fallar. (Cf. otros datos en la autobiografía que escribió para Historia y antología 
del cuento y la novela en Hispanoamérica, de Angel Flores, pp. 503-504). Los siguientes son sus libros de ficción:

Agua, Lima, 1935.

Yawar Fiesta, Lima, 1941, y corregida 1958.

Diamantes y pedemales, Lima, Mejía Baca, 1964. (Consigna un importante prólogo del autor.)

Los rios profundos, Buenos Aires, Losada, 1958.

El sexto, Lima, Mejía Baca, 1961.

Todas las sangres, Buenos Aires, Losada, 1964.

Amor mundo y todos los cuentos de José Maria Arguedas, Lima, Francisco Moncloa Editores, 1967.

De El zorro de arriba y el zorro de abajo, que editará Losada, han aparecido fragmentos en Amaru (Lima, No. 6, abril-junio, 1968) y en Cuadernos semestrates de cuento (Lima, No. 5, julio, 1969).

Entre sus recopilaciones y artícu'os sobre el pueblo quechua y su literatura, se cuentan:

Canto Kechwa ("Con un ensayo sobre la capacidad de creación artística del pueblo indio y mestizo"), Lima, 1938.

Mitos, leyendas y cuentos peruanos (en colaboración con Francisco Izquierdo Ríos), Lima, 1947.

Canciones y cuentos del pueblo quecbua, Lima, Editorial Huascarán, 1949.

Cuentos mágico-realistas y canciones de fiestas tradicionales en el valle del Mantaro, Lima, 1953.

"Folklore del Valle del Mantaro", en Folklore Americano, No. 1, Lima, 1953.

"Cuentos religioso-mágicos de Lucanamarca", en Folklore Americano, Nos. 8-9, Lima, 1960.

"La soledad cósmica en la poesía quechua", en Casa de las Américas, La Habana, Año II, Nos. 15-16, 1962-1963, pp. 15-25.

Dioses y hombres de Huarocbiví (Prólogo y traducción del quechua de José María Arguedas) Lima, Museo Nacional de Historia e Instituto de Estudios Peruanos, 1966. (Una de las más importantes relaciones sobre la mitología peruana.)

Poesía quechua (Prólogo de J. M. A.) Lima, Ediciones de la Bibliotecá Universitaria, 1967.

"Mitos quechuas pos-hispánicos", en Amaru, Lima, No. 3, julio-septiembre, 1967, pp. 14-18. 
Las comunidades de España y del Perú, Lima, Universidad de San Mar. cos, 1968.

Para una visión crítica de la obra de Arguedas se puede consultar los textos siguientes:

Aldrich, Earl M.: The Modern Short Story in Perú, University of Winsconsin Press, 1966, pp. 127-140.

Castro Klaren, Sara: "Todos los cuentos de Arguedas", en Amaru, Lima, No. 2, abril, 1967, pp. 87-89.

Coulthard, G. R.: "Arguedas: un problema de estilo", en Mundo Nuevo, París, No. 19, enero, 1968, pp. 73-78.

Escobar, Alberto: "La guerra silenciosa de Todas las sangres", en Re. vista Peruana de Cultura, Lima, No. 5, abril, 1965, pp. 37-49.

Ortega, Julio: "Dos notas sobre José María Arguedas", en La contemplación y la fiesta, Monte Avila Editores, 1969, pp. 57-75.

31, enero, 1969, pp. 44-58.

Oviedo, José Miguel: "Un vasto cuadro del Perú feudal" (sobre T'odas las sangres), en Suplemento de El Comercio, Lima, noviembre 11 de 1965.

Rouillon, José Luis: "Notas sobre el mundo mágico de José María Arguedas", en Mercurio Peruano, No. 461, mayo-junio, 1966, pp. 121-133.

Salazar Bondy, Sebastián: "Arguedas: la novela social como creación verbal", en Revista de la Universidad de México, vol. XIX, No. 11, julio, 1965, pp. 18-20.

Vargas Llosa, Mario: "José María Arguedas y el indio", Prólogo a Los rios profundos, La Habana, Casa de las Américas, 1965.

-_: "Ensoñación y magia en José María Arguedas", Prólogo a Las rios profundos, Santiago de Chile, Editorial Universitaria, 2da. edición, 1969.

Yurkievich, Saúl: "José María Arguedas: encuentro con una narrativa americana", en Cuademos Americanos, 1963.

\section{Adnenda II: Declaración de Máximo Damín Huamaní}

En la carta que escribió antes de suicidarse, Arguedas pidió que su amigo Máximo Damián Huamaní tocara el violín durante su entierro. Huamani y sus músicos tocaron y danzaron, presidiendo el cortejo fúnebre. El Dominical de El Comercio (Lima, 7-XII-69), publicó una 
declaración de Máximo Damián Huamaní, que es uno de los homenajes más sencillos y elocuentes hechos en la muerte de Arguedas.

\section{EL VIOLINISTA QUE ACOMPAÑó a ARgUEDAS}

"Yo soy Máximo Damián Huamani, el mencionado, el que pidió que tocara mi violín en su entierro. Abi estuve, pues, tocándole "Agonia" que es muy triste porque es la muerte del danzante. "Huallpa wajai" que le gustaba mucbo cuando vivo.

El marles 2 lo vi. Teniamos cita en la Plaza San Martin, me estaba hablando de un libro kecbua para bacer. En junio nomás, babia llegado yo de Huarmillacta, Parinacochas, donde vive pura mujer, nomás. El quería saber de eso. Interesddo estaba. Muy interesado.

Yo llegué a Lima de mi pueblo San Diego de Isbua y a él recurrí, antes del Museo. Yo queria que me pasaran por televisión, el vio los danzantes y oyó mi violin. Nos bizo pasar por canal de Educación Püblica.

El 23 de noviembre estuvo en Balconcillo, calle Esmeraldas, abí estábamos todos reunidos, los paisanos en la fiesta de San Diego de Isbua, fiesta de San Isidro labrador, el Grande. Con un cubano fue, que era su amigo y un francés y un tal Alejandro Ortiz, escritor decia que era. Abí bailó don José María el buaino "Karamusa" que muy alegre es, alegre asi, de alegría. Abi vio a los danzantes ayacuchanos de mi pueblo danzar sobre el violin, sobre el arpa, sin romperlos, asi, pies de seda, nomás.

De dónde para saber que se estaba despidiendo, estaba diciendo adiós al buaino. Don José Maria iba a almorzar a mi casa, a mi callejón de Pueblo Libre, el entraba nomás, que importaban bask$r a$, moscas, pobreza. Comía mucho, almorzaba comida de mi pueblo San Diego de Ishua, comía patasquita, barto, o "tinke" que es un mezclado de habas, alverjas, queso, queso nomás le gustaba. Era bueno el doctor, be llorado su muerte, de a verdad como lloramos en mi tierra, con lágrimas, no con fingimientos.

Con mi papá también era gran amigo, mi papá también es paisanito, lo llevaba al Bolivar, abi comian, qué importa que oigan los gringos bablar quecbua, bablan fuerte para que todos oigan. Mi papá no tiene noticia de esta muerte, pero lamento babrá cuando lo sepa. 
Años, años que me llamaba, me bablaba, ven con tu violin o yo voy a ir a tu casa, abi lo esperaba en casa de mi tía Vicenta Santiago que tiene puesto de verdura en Pueblo Libre, yo le ayudo en eso; el queria ponerme en algún puesto decente, mayordomo no, decia, un puesto, asi de trabajador no de muchacbo; aqui es muy dificil, injusticias son todas nomás, decía.

Yo ando solo, a veces los paisanos cuando bay fiesta, pero lo más del tiempo, solo, solo como buérfano. Abi, me iba a buscarlo. nunca me dijo ándate ya, más bien me decía quédate y almorzábamos primero en Pueblo Libre, después en Santa Cruz, al último ya en. Chaclacayo, su señora es testiga de sus alegrias, de sus pesares. Una vez estuvo muy alegne, en fiesta de "Karguyoc", tomaba cbicha con todos, sin escogimientos, contigo salud, con el otro, con los danzantes, con los que le decian salud doctor Arguedas; el tocaba el arpa, se hacía el que le sacaba dulzuras al arpa, mi compadre Guzmán López se reía de sus becburas de caballero, de bombre bueno, paisano.

He de llevar este luto por seis meses a la costumbre de mi pueblo San Diego de Ishua, pero qué, con esto no acabará mi pena. He sufrido bastante $y$ be llorado, por qué no pues, él erct como una familia.

Ese último dia martes 2 que lo vi en Plaza San Martin, me dijo que lo iha a ver el vienes 5 a las 7 en Pueblo Libre casa de mi tía Vicenta Santiago. Yo lo esperé con mi violin, queria preguntarme de quecbua, barto le enseñé yo cosas que no sabía, queria saber del pueblo de pura mujer, pueblo parinacochano. Estaba ensayando en mi violin aires de danzantes de tijeras, dieron las 8 , las 9, no llegó Nunca tardaba, cumplido era él. A las $10 \mathrm{mi}$ tia me gritó que apague la vela, siempre tenia pena de mi cuartito abi en la miseria, se quejaba, decia que así está destinado para nosotros los indigenas. Lo esperé mucbo y sentí mucha pena.

Corazonadas, pues. El no fue porque ya estaba peleando con la muerte, en el bospital. Al otro dia, todo fue obscuro para mi, yo era su amigo, su violinista, por qué esa determinación, siento bastante, abora me parece que estoy desamparado aqui, solo".

\section{Julio Ortega}

University of Pittsburgh 